\title{
Structurally Diverse Substance
}

National Cancer Institute

\section{Source}

National Cancer Institute. Structurally Diverse Substance. NCI Thesaurus. Code C103206.

A type of polydisperse substance isolated from a single source that is a complex mixture which cannot be described as a limited set of single substance. 